\title{
Understanding the Learning and Innovation Model of Exhibition Visitors
}

\author{
Yanan Zhou, Junxia Liu, Wanyun Zhang, Peng Ju* \\ Shenzhen Tourism College of Jinan University, Shenzhen, China \\ Email: *jjppsszz@163.com
}

How to cite this paper: Zhou, Y. N., Liu, J. X., Zhang, W. Y., \& Ju, P. (2020). Understanding the Learning and Innovation Model of Exhibition Visitors. American Journal of Industrial and Business Management, 10, 824-840.

https://doi.org/10.4236/ajibm.2020.104056

Received: April 5, 2020

Accepted: April 26, 2020

Published: April 29, 2020

Copyright $\odot 2020$ by author(s) and Scientific Research Publishing Inc. This work is licensed under the Creative Commons Attribution International License (CC BY 4.0).

http://creativecommons.org/licenses/by/4.0/

\begin{abstract}
Research on visitors tends to focus on the behavior of the audience before and after the exhibition, while there is little research on the behavior of audiences in the exhibition. The learning and innovative behavior of visitors at the exhibition also reflects one of the basic functions of the exhibition: communicating and Disseminating information. This paper based on the domestic and international research literature on the knowledge diffusion of exhibitions and uses SEM to the established model of the visitors' learning and innovative behavior in exhibition. The validity of the path in the model is tested by taking Shenzhen Machinery Exhibition as a case. The results show that visitors have different learning behaviors for suppliers and other visitors, resulting in different learning and innovation effects. In addition, their positions, frequency of visiting exhibitions and forms of their visits also have an impact on their learning behaviors.
\end{abstract}

\section{Keywords}

Exhibition, Visitors, Learning, Innovation

\section{Literature Review}

\subsection{Exhibition Visitors}

The studies of exhibition visitors focus on their behaviors of pre-exhibition decision-making, during-exhibition visiting and post-exhibition evaluation.

Studies on the pre-exhibition decision-making behavior of exhibition visitors mainly focused on their visiting motivation and the analysis of influential factors. Qiao (2012) and Guo (2011) studied the influential factors of visitors' visiting decisions, and found that the influential factors ranked as follows: popularity and relevance of exhibits, expectation of information acquisition, situations of previous exhibitions, technological expectations, purchasing and seeking coop- 
eration, locations, publicity and invitation, costs of visiting the exhibition.

Studies on the during-exhibition visiting behavior of exhibition visitors involved the visiting itinerary, types of searched information, decisions of purchasing exhibits and their interaction with other exhibition participants. Among them, there were more studies of types of searched information than those of other three subjects. Bathelt \& Gibson (2015) divided four types of information search behavior of visitors by the method of semi-structured interviews with "fuzzy and unstructured", "fuzzy but positive", "confident but fuzzy", "clear and structured". In the study of the visiting itinerary of visitors, Jia (2012) found that the factors of "images of the booth staff", "display of the exhibits", "the market relationship", "values of the exhibits", "display of the booths", and "publicity of the exhibitors" had impacts on both visiting routes and choices of visiting booths of visitors. Wang (2014) studied the interaction of visitors and other exhibition participants.

Studies on the post-exhibition evaluation of exhibition visitors aimed at their perceived service quality (Chi, 2013), satisfaction (Li, 2017; Zhao, 2016), the revisiting willingness (Liu, 2015) and the relationship among the above three aspects (Ji, 2012). American Customer Satisfaction Index (ACSI) assessment model and the SERVQUAL scale have been widely used as the basis of the assessment model of visitors' satisfaction by many scholars. Their satisfaction can be divided into five dimensions: tangibility, reliability, responsiveness, assurance and empathy. Among them, there was an indicator of empathy, "the participation of advanced technologies and giant enterprises", showing that visitors' learning of advanced technologies, that was, innovation, was also part of their satisfaction.

\subsection{Mechanism of Exhibition Knowledge Diffusion}

\subsubsection{Elements of Exhibition Knowledge Diffusion}

Scholars had different explanations of the elements of exhibition knowledge diffusion. Zhong \& Luo (2018) stated that the mechanism of exhibition knowledge diffusion included knowledge providers and knowledge receivers with four major elements: media, content, interaction and context.

Bathelt, Malmberg, \& Maskell (2002) interpreted the context of knowledge diffusion as "global buzz" and "global knowledge pipeline". "Global buzzing" referred to the information and communication atmosphere created by people or enterprises from the same industry through face-to-face conversations or gathering. "Global knowledge pipeline" referred to the channels used for long-distance interaction, which transferred new knowledge into the "buzzer". The results showed that "global buzz" and "global knowledge pipeline" can promote each other, jointly promote innovation and build a good interactive ecology. Zhu, Chen, \& Lian (2018) explored the relationships among "global buzz", "global knowledge pipeline" and innovation with the structural equation model, and conducted the empirical study on the innovation internal model of creative exhibitions such as Beijing Design Week. 
Boschma \& Ter Wal (2007) stated that content elements of mechanism of exhibition knowledge diffusion can be divided into market strategy knowledge and technological knowledge. During the exhibition, exhibitors and visitors communicated the problems in the use of existing products and explored products' improvement and the application of new technologies (Borghini, Golfetto, \& Rinallo, 2006). As the products of the same industry chain were displayed at the same time and place, exhibitors and visitors can also discover the industry's development trends of technology and market by observing and comparing different exhibits. The participants with continuous exhibition experiences can also discover technology and market trends by comparing the exhibits displayed in different sessions of exhibitions.

\subsubsection{Structural Relationship among the Elements}

Zhong and Luo (2018) classified the interaction among exhibition elements as "the interaction between exhibits and participants" and "the interaction among participants". With regard to face-to-face communication, Rogers (2016), an American scholar, put forward the innovation diffusion theory of persuading people to accept new ideas, new things and new products through media in 1983. Base on this theory, he divided the innovation diffusion process from the source to receivers into five stages: cognition, persuasion, decision-making, implementation and confirmation. Rogers divided communication channels into interpersonal channels and mass communication channels represented by newspapers, television and the Internet. Interpersonal channels can be understood as word-of-mouth publicity. In the cognitive stage, mass communication channels enabled more people to find the innovation. However, people also needed to be persuaded through interpersonal channels in order to accept this innovation.

Storper and Venables (2004) believed that face-to-face communication conveyed more complex information than words, pictures, etc., and enabled communicators to get rapid feedback. Polanyi (1967) stated that the diffusion of explicit knowledge was mainly through the mass media, and the diffusion of implicit knowledge must be through face-to-face communication. Nonaka, Toyama, and Konno (2000) found that the creation and transformation of knowledge was a dynamic process among four modes of knowledge transformation: imperceptible influence (socialization), external explicitness (externalization), aggregate integration (integration) and internal sublimation (internalization).

Exhibition participants can obtain important information not only through direct face-to-face communication, but also through indirect observation. Bandura, one of the American psychologists, put forward the social learning theory, and found that most of people's behavior was learned by observing the surrounding environment and the behavior of others (Albert, 2014). Borghini, Golfetto, and Rinallo (2006) found that exhibitors skimmed other booths during the exhibition and carefully observed the behavior of other exhibitors, such as interaction with visitors, marketing mode, etc. Through observation and study, exhibitors quickly learned the market strategies of their competitors and provided 
reference for their own development strategies.

Luo \& Zhong (2016) analyzed the network structure of exhibition knowledge diffusion with the method of social network analysis. The results showed that the exhibition knowledge diffusion was flat, coherent, efficient and uneven. In the exhibition, there was more knowledge diffusion of market promotion strategies, and more attention was gathered to enterprises with strong research and development capabilities.

\subsubsection{The Running Mode of the Elements}

Studies on exhibition knowledge transfer focused on the information collection of exhibitors or visitors, that is, the information search stage of innovation diffusion proposed by E. M. Rogrers. For example, Borghini, Golfetto, and Rinallo (2006) studied the nature of information search behavior of exhibition visitors, such as the results of information search and its experience through ethnographic methods. The results showed that the exhibition knowledge was transferred from the providers of knowledge experience (exhibitors and organizers) to the visitors and had a broader impact through their search behavior. Visitors' exhibition knowledge experience came from two aspects: exhibitors (exhibitors' products, human resources and other customers) and organizers (atmosphere, choices of exhibitors and trends). There were four types of search results: acquisition of unexpected knowledge, inspiration, reconfirmation of existing suppliers, establishment and maintenance of relationships.

Shan, Zeng, \& Zhu (2014) found that there were four ways for participants to acquire new knowledge in the temporary cluster of China International Industrial Fair in Shanghai: talking to each other, meeting new customers and establishing contacts, observing directly or indirectly, and obtaining market trends. Through participants' post-exhibition application of new knowledge, the technological innovation was promoted at last.

On the basis of summarizing previous studies, Zhu and Zeng (2017) divided the interactive learning process of exhibitors into three levels (object-action-effect), and found that the effects of the action layer differ with different objects such as customers, partners and competitors.

\subsubsection{Influential Factors of Exhibition Knowledge Diffusion Based on Knowledge Transfer Theory}

There were many influential factors of effects of knowledge diffusion. Among them, the relatively comprehensive influential factors were concluded in the model of knowledge transfer analysis framework proposed by Albino and the four-element model of knowledge transfer proposed by Cummlngs \& Teng. The four elements included knowledge providers and knowledge receivers (the two subjects); transferred knowledge (the object); and the transferred media/channels and situations. Iris made a special research on the element of transfer situations, regarded the forum as a cross-organizational community of practice, and divided the situations of knowledge sharing into formal occasion and informal 
occasion. Also, the process of knowledge sharing in these two situations and the impact of information technology usage on knowledge sharing in international conferences were studied respectively.

$\mathrm{Li}$ (2018) constructed the structural equation model based on the four-element model and explored the influential factors of the exhibition knowledge transfer effect through questionnaire survey and data analysis. The results showed that there were three major influential factors: knowledge attribute, transfer ability and transfer situation. Reychav (2009) found that exhibition knowledge sharing had an impact on knowledge acquisition through three intermediary variables: joint action, exhibitors' recognition and visitors' recognition, and exhibitors and visitors were in different approaches of exhibitions.

In a word, the influential factors of exhibition knowledge diffusion can be divided into two types in previous studies. One was the attribute of knowledge itself, and the other was the attribute of relationship network formed in the process of people's interaction, such as relationship strength, relationship quality, characteristics of relationship network structure.

\section{Research Design and Methods}

\subsection{Research Object}

The research object in this study is the visitors of Shenzhen International Industrial Manufacturing Technology Exhibition. On March 28th, 2019, the Shenzhen International Furniture Exhibition opened with the duration of 4 days with an exhibition area of 110,000 square meters. 1155 exhibitors and 86,983 visitors participated in this exhibition. The exhibits included intelligent equipment, automation applications, flexible production, system integration and other mechanical manufacturing and metal processing.

Shenzhen International Industrial Manufacturing Technology Exhibition, which has been held for 20 years, is an exhibition with the largest scale, the highest technological contents, the widest categories and the best demonstration effect in the field of manufacturing equipment in South China. The data can be collected conveniently because of its long duration and high flow of participants. In addition, the macro information of this exhibition can be obtained from the detailed post-exhibition reports on the official website of Shenzhen International Industrial Manufacturing Technology Exhibition. So, the research location has been determined at this exhibition.

\subsection{Research Methods}

Based on innovation diffusion theory and social learning theory, the data was collected through questionnaire survey, and structural equation model was used to test and analyze each specific path of the constructed model.

\subsection{Design of Structural Equation Model}

With the references of the exhibitors' path model of learning and innovation 
process proposed by Zhu \& Zeng (2017) and the information search behavior model of exhibition visitors proposed by Borghini et al. (2006), the path model of exhibition visitors' learning and innovation has been designed (Figure 1).

\subsection{Questionnaire Design and Pre-Survey}

\subsubsection{Questionnaire Design}

Bollen (1989) stated that the scale should be as larger as needed, and the 7-point Likert scale should be widely used in the structural equation model. In each potential facet, there should be at least 3 items, of which $5-7$ items are preferable. According to the above study, 7-point Likert scale has been used in this study, and the observed variables of the latent variables were extracted from the qualitative research conclusions of Borghini et al. (2006). In this study, there were 21 quantified scale items and 7 items of demographic information, a total of 28 items in the questionnaire (Table 1).

\subsubsection{Pre-Survey and Formal Questionnaire}

In pre-survey, 74 questionnaires were collected by e-mails, of 74 valid.

The Cronbach's $\alpha$ coefficient was used to test the reliability of the internal consistency of the scale. In this study, the Cronbach's $\alpha$ coefficient is 0.917 , greater than 0.9 . The reliability coefficient values of the deleted items have not been significantly improved, and the CITC values of all items are greater than 0.4 . The above data shows that the collected data is in high reliability, each item should be retained, and there exists a good correlation among the analysis items. The data with high reliability can be used for further analysis.

Exploratory factor analysis and confirmatory factor analysis were used to test the construct validity of the scale. The KMO value is 0.796 , greater than 0.7 , and the $P$-value is less than 0.05 , indicating that the questionnaire data has good structural validity and can be used for structural equation model analysis.

\section{Data Analysis and Conclusions}

\subsection{Descriptive Statistics}

The formal questionnaires were distributed by sending e-mails to the visitors of Shenzhen International Industrial Manufacturing Technology Exhibition and handing out questionnaires in the Intelligent Manufacturing Forum, and a total of 335 questionnaires were collected, of 324 valid. The descriptive statistical characteristics are as follows (Table 2):

1) the vast majority of visitors have more than 2 times of exhibition experience with 2 - 5 times a year, with a percentage of $69.1 \%$, indicating that most visitors selectively participate in exhibitions with the needs of their enterprises.

2) most visitors are service providers (34\%) and distributors/agents (24.1\%), and a small number of them are manufacturers (18.8\%). It indicates that most visitors are downstream customers or partners of exhibitors. 


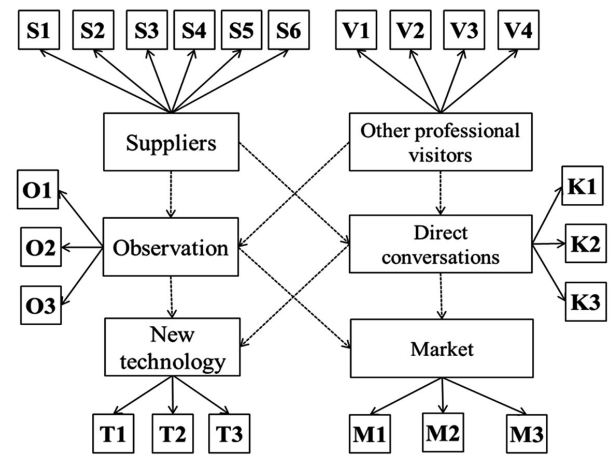

Figure 1. The learning and innovation model of exhibition visitors.

Table 1. The scale of learning and innovation of visitors.

\begin{tabular}{|c|c|c|c|}
\hline $\begin{array}{l}\text { Model } \\
\text { levels }\end{array}$ & $\begin{array}{l}\text { Questionnaire } \\
\text { contents }\end{array}$ & Variables & References \\
\hline \multirow{9}{*}{$\begin{array}{l}\text { Object } \\
\text { level }\end{array}$} & \multirow{5}{*}{$\begin{array}{l}\text { Communicating } \\
\text { with } \\
\text { suppliers }\end{array}$} & Details of products technology & \multirow{9}{*}{$\begin{array}{l}\text { Zhu \& Zeng } \\
\text { (2017); } \\
\text { Borghini et al. } \\
(2006)\end{array}$} \\
\hline & & Problems in the use of existing products & \\
\hline & & Current situation of the industry market & \\
\hline & & Technological progress in the industry & \\
\hline & & Relationship maintenance with existing suppliers & \\
\hline & \multirow{4}{*}{$\begin{array}{l}\text { Communicating } \\
\text { with } \\
\text { other visitors }\end{array}$} & $\begin{array}{l}\text { Relationship construction with potential suppliers } \\
\text { News on the management/strategy } \\
\text { of top enterprises in the industry }\end{array}$ & \\
\hline & & Ideas on the application prospect of new technology & \\
\hline & & Common problems & \\
\hline & & Relationship construction with other visitors & \\
\hline \multirow{6}{*}{$\begin{array}{l}\text { Action } \\
\text { level }\end{array}$} & \multirow{3}{*}{$\begin{array}{l}\text { Direct } \\
\text { conversations }\end{array}$} & Talking about the current situation of the industry & Interviews \\
\hline & & $\begin{array}{l}\text { Talking about the technological/conceptual } \\
\text { progress of the industry }\end{array}$ & \multirow{5}{*}{$\begin{array}{l}\text { Zhu \& Zeng } \\
\text { (2017); } \\
\text { Borghini, Gol- } \\
\text { fetto, and Ri- } \\
\text { nallo (2006) }\end{array}$} \\
\hline & & Talking about the future trend of the industry & \\
\hline & \multirow{3}{*}{$\begin{array}{l}\text { Direct/Indirect } \\
\text { observation }\end{array}$} & Observing the communication of others & \\
\hline & & $\begin{array}{l}\text { Observing and comparing the concepts of products } \\
\text { design, advantages and disadvantages of products }\end{array}$ & \\
\hline & & $\begin{array}{l}\text { Observing and summarizing the distribution } \\
\text { of exhibits }\end{array}$ & \\
\hline \multirow{6}{*}{$\begin{array}{l}\text { Effect } \\
\text { level }\end{array}$} & \multirow{3}{*}{ New technology } & Solutions to existing problems & \multirow{6}{*}{$\begin{array}{l}\text { Borghini, Gol- } \\
\text { fetto, and Ri- } \\
\text { nallo (2006); } \\
\text { Zhu \& Zeng } \\
\text { (2017) }\end{array}$} \\
\hline & & Basic information of new technology & \\
\hline & & $\begin{array}{l}\text { Promoting products innovation according } \\
\text { to new technology }\end{array}$ & \\
\hline & \multirow{3}{*}{ Market } & $\begin{array}{l}\text { Having access to new market opportunities } \\
\text { information }\end{array}$ & \\
\hline & & Grasping the new trend of market development & \\
\hline & & $\begin{array}{l}\text { Getting inspiration for products development or } \\
\text { service innovation according to new market } \\
\text { opportunities or development trends }\end{array}$ & \\
\hline
\end{tabular}


Table 2. The descriptive statistical characteristics of the samples.

\begin{tabular}{llll}
\hline Characteristics & Classification & Frequency & Percentage \\
\hline Times of exhibition & 1 & 50 & 15.4 \\
experience in 1 year & $6-5$ & 224 & 69.1 \\
& $>10$ & 39 & 12 \\
& proportions of buyers & 11 & 3.4 \\
& technicians & 30 & 9.3 \\
Positions of the visitors & sales staff & 40 & 12.3 \\
& functional department staff & 107 & 32.7 \\
& Middle and senior management & 41 & 33 \\
& personal & 133 & 12.7 \\
Visiting form & Group & 191 & 41 \\
& manufacturer & 61 & 59 \\
Company nature & service providers & 78 & 18.8 \\
& service providers & 110 & 24.1 \\
& All of them have & 70 & 34 \\
& Others & 5 & 21.6 \\
\hline
\end{tabular}

3) positions of most visitors are sales staff (32.7\%) and functional department staff (33\%), and the proportions of buyers (9.3\%) and technicians $(12.3 \%)$ are relatively small. It indicates that the main visiting purpose of most visitors is to collect information.

\subsection{Reliability and Validity Testing}

The Cronbach's $\alpha$ coefficient was used to test the reliability of the internal consistency of the formal scale. The Cronbach's $\alpha$ coefficient is 0.973 , greater than 0.9 , and the formal questionnaire data is in a good reliability. The KMO value is 0.942 , greater than 0.7 , and the $P$-value is less than 0.05 , indicating that the formal questionnaire data has good structural validity and can be used for structural equation model analysis.

\subsection{Difference Analysis}

One-way ANOVA was used to analyze the difference. The mean values of the observed variables of each latent variable were calculated, and the difference analysis was carried out by taking the mean values as of latent variables.

\subsubsection{The Impacts of Positions on Both Learning Styles and Effects}

The results of one-way ANOVA of positions on learning styles and effects show that the $p$-value of "visitors in different positions" to "direct conversations" is 0.05 , less than 0.1 , indicating that there exists significant difference in the learn- 
ing style of direct conversations among visitors in different positions. The $p$-values of observation ( $p=0.981)$, acquiring technological knowledge ( $p=$ $0.521)$ and acquiring market knowledge $(p=0.190)$ are all greater than 0.1 , indicating that there exists no significant difference in the learning style of observation, and acquiring technological and market knowledge among visitors in different positions.

In view of the significant difference in direct conversations among visitors in different positions, the Tukey's post hoc testing was conducted (detailed results in Table 3).

The results show that there exists difference in direct conversations between "buyer" and "other positions" of visitors. Combined with the calculated mean values, it is found that the mean value of "buyer" indirect conversations is 4.36, lower than those of "other positions", and the buyers in visitors are less likely to have direct conversations for learning. On the other hand, the mean values of technicians and middle and senior managers are higher in these five positions, and they prefer to learn through direct conversations.

\subsubsection{The Impacts of Types of Enterprises on Both Learning Styles and Effects}

One-way ANOVA results (Table 4) of types of enterprises on learning styles and effects show that: $p$ values of learning styles and effects are both greater than 0.1, indicating that there is no significant difference in learning styles and effects among visitors of different types of enterprises.

\subsubsection{The Impacts of Visiting Forms on Both Learning Styles and Effects} Visiting forms can be divided into "visiting alone" and "visiting in groups". The results (Table 5) show that Sig. (bilateral) of "learning from suppliers", "observation", and "acquiring technological and market knowledge" are all less than 0.1 , indicating that there exists significant difference of the above three factors between "visiting alone" and "visiting in groups". By comparison of their mean values, the results show that visitors visiting in groups learn more from suppliers, have more observation and learning behavior and acquire more technological and market knowledge than those visiting alone.

\subsection{Fitting and Debugging of Structural Equation Model}

Based on the structural equation model design mentioned above, 324 samples were calculated and analyzed in the model. The results show that the chi-square value $\left(\chi^{2}\right)$ of the initial model is 376.661 , the degree of freedom (df) is 199 , and the ratio of chi-square value to degree of freedom $\left(\chi^{2} / \mathrm{df}\right)$ is 1.893 . The initial model is in a medium fitting degree, and needs to be further debugged and optimized.

In order to optimize the initial model, the correction index of MI is analyzed, and the paths of residual errors of "e3 - e4", "e5 - e6" and "e17 - e19" are added. Combined with the path coefficients and the actual situation of the exhibition, 
the path of "visitors to direct conversation" is deleted. After the above operation, all path coefficients are positive and significant. The modified conceptual model paths are obtained in Table 6.

In the modified model, the Chi-square value $\left(\chi^{2}\right)$ is 356.101 , the degree of freedom ( $\mathrm{df}$ ) is 198 , and the ratio of chi-square value to degree of freedom $\left(\chi^{2} / \mathrm{df}\right)$ is 1.798 . The fitting degree is higher than that of the initial model (in Table 7). The results of the specific coefficients and test values of the modified model can be seen in Table 7, in which each path coefficient is positive and the significance of each coefficient is less than or equal to the standard of 0.05 . At last, the initial model has been debugged and the final model paths have been obtained.

Table 3. Tukey's post hoc testing of direct conversations.

\begin{tabular}{cccc}
\hline & \multicolumn{3}{c}{ Subsets of "alpha $=0.05$ ” } \\
\hline Positions & $\mathrm{N}$ & 1 & 2 \\
\hline Buyer & 21 & 4.3636 & 4.8821 \\
Functional department staff & 31 & 4.8821 & 4.9909 \\
Sales staff & 88 & 4.9909 & 5.1852 \\
Technician & 82 & & 5.2111 \\
Middle and senior manager & 34 & & 0.749 \\
Significance & & 0.151 & \\
\hline
\end{tabular}

The group mean values in the same subset are displayed. a. The harmonic mean value of the sample size = 29.024 is used. b. The sizes of groups are not equal. The harmonic mean values of the group sizes are used. Type I error level is not guaranteed.

Table 4. One-way ANOVA of types of enterprises on learning styles and effects.

\begin{tabular}{|c|c|c|c|c|c|c|}
\hline & & Sums of squares & $\mathrm{df}$ & Mean variances & $\mathrm{F}$ & Significance \\
\hline \multirow{3}{*}{ Technology } & Intergroup & 4.903 & 4 & 1.226 & 1.392 & 0.236 \\
\hline & Within the group & 280.848 & 319 & 0.88 & & \\
\hline & Total & 285.752 & 323 & & & \\
\hline \multirow{3}{*}{ Market } & Intergroup & 1.26 & 4 & 0.315 & 0.353 & 0.842 \\
\hline & Within the group & 284.796 & 319 & 0.893 & & \\
\hline & Total & 286.056 & 323 & & & \\
\hline \multirow{3}{*}{$\begin{array}{c}\text { Direct } \\
\text { conversations }\end{array}$} & Intergroup & 4.335 & 4 & 1.084 & 1.047 & 0.383 \\
\hline & Within the group & 330.22 & 319 & 1.035 & & \\
\hline & Total & 334.555 & 323 & & & \\
\hline \multirow{3}{*}{ Observation } & Intergroup & 4.666 & 4 & 1.167 & 1.277 & 0.279 \\
\hline & Within the group & 291.433 & 319 & 0.914 & & \\
\hline & Total & 296.099 & 323 & & & \\
\hline
\end{tabular}


Table 5. Independent sample $\mathrm{T}$ testing of visiting forms, learning objects, styles and effects.

\begin{tabular}{|c|c|c|c|c|c|c|c|c|}
\hline \multicolumn{9}{|c|}{ T-test of mean equation } \\
\hline \multirow{2}{*}{ Variables } & \multirow{2}{*}{ Hypotheses } & \multirow{2}{*}{$\mathrm{T}$} & \multirow{2}{*}{ df } & \multirow{2}{*}{$\begin{array}{c}\text { Sig. } \\
\text { (bilateral) }\end{array}$} & \multirow{2}{*}{$\begin{array}{c}\text { Mean } \\
\text { difference }\end{array}$} & \multirow{2}{*}{ S.E. } & \multicolumn{2}{|c|}{$\begin{array}{c}95 \% \text { confidence } \\
\text { interval of difference }\end{array}$} \\
\hline & & & & & & & $\begin{array}{l}\text { Lower } \\
\text { limits }\end{array}$ & $\begin{array}{l}\text { Upper } \\
\text { limits }\end{array}$ \\
\hline \multirow{2}{*}{ Suppliers } & $\begin{array}{c}\text { Equal } \\
\text { variance }\end{array}$ & -3.188 & 322 & 0.002 & -0.33765 & 0.10592 & -0.54603 & -0.12927 \\
\hline & $\begin{array}{l}\text { Unequal } \\
\text { variance }\end{array}$ & -3.1 & 254.653 & 0.002 & -0.33765 & 0.10893 & -0.55216 & -0.12314 \\
\hline \multirow{2}{*}{$\begin{array}{l}\text { Other } \\
\text { visitors }\end{array}$} & $\begin{array}{c}\text { Equal } \\
\text { variance }\end{array}$ & -1.637 & 322 & 0.103 & -0.18169 & 0.11099 & -0.40004 & 0.03666 \\
\hline & $\begin{array}{l}\text { Unequal } \\
\text { variance }\end{array}$ & -1.612 & 268.439 & 0.108 & -0.18169 & 0.11268 & -0.40354 & 0.04015 \\
\hline \multirow{2}{*}{$\begin{array}{c}\text { Direct } \\
\text { conversations }\end{array}$} & $\begin{array}{c}\text { Equal } \\
\text { variance }\end{array}$ & -1.628 & 322 & 0.104 & -0.18668 & 0.11465 & -0.41223 & 0.03886 \\
\hline & $\begin{array}{l}\text { Unequal } \\
\text { variance }\end{array}$ & -1.607 & 270.575 & 0.109 & -0.18668 & 0.11616 & -0.41537 & 0.042 \\
\hline \multirow{2}{*}{ Observation } & $\begin{array}{c}\text { Equal } \\
\text { variance }\end{array}$ & -1.856 & 322 & 0.064 & -0.19998 & 0.10772 & -0.41191 & 0.01195 \\
\hline & $\begin{array}{l}\text { Unequal } \\
\text { variance }\end{array}$ & -1.841 & 275.546 & 0.067 & -0.19998 & 0.10863 & -0.41382 & 0.01387 \\
\hline \multirow{2}{*}{$\begin{array}{c}\text { Effect of } \\
\text { technology }\end{array}$} & $\begin{array}{c}\text { Equal } \\
\text { variance }\end{array}$ & -1.999 & 322 & 0.046 & -0.21134 & 0.10574 & -0.41936 & -0.00332 \\
\hline & $\begin{array}{l}\text { Unequal } \\
\text { variance }\end{array}$ & -2.055 & 308.589 & 0.041 & -0.21134 & 0.10284 & -0.41369 & -0.00899 \\
\hline \multirow{2}{*}{$\begin{array}{l}\text { Effect of } \\
\text { market } \\
\text { trends }\end{array}$} & $\begin{array}{c}\text { Equal } \\
\text { variance }\end{array}$ & -3.081 & 322 & 0.002 & -0.32324 & 0.10491 & -0.52964 & -0.11685 \\
\hline & $\begin{array}{l}\text { Unequal } \\
\text { variance }\end{array}$ & -3.077 & 282.619 & 0.002 & -0.32324 & 0.10507 & -0.53006 & -0.11643 \\
\hline
\end{tabular}

Table 6. Regression weights of the modified model.

\begin{tabular}{|c|c|c|c|c|c|c|}
\hline & ths & & Estimate & S.E. & C.R. & $P$ \\
\hline Direct conversations & $<---$ & Suppliers & 0.747 & 0.077 & 9.706 & $* * *$ \\
\hline Observation & $<---$ & Other visitors & 0.579 & 0.145 & 3.989 & $* * *$ \\
\hline Observation & $<---$ & Suppliers & 0.341 & 0.115 & 2.973 & 0.003 \\
\hline Technology & $<---$ & $\begin{array}{c}\text { Direct } \\
\text { conversations }\end{array}$ & 0.587 & 0.11 & 5.34 & $* * *$ \\
\hline Technology & $<---$ & Observation & 0.462 & 0.103 & 4.47 & $* * *$ \\
\hline Market & $<---$ & Observation & 0.535 & 0.117 & 4.586 & $* * *$ \\
\hline Market & $<---$ & $\begin{array}{c}\text { Direct } \\
\text { conversations }\end{array}$ & 0.393 & 0.113 & 3.469 & $* * *$ \\
\hline
\end{tabular}


Table 7. Comparison of coefficients between initial model and modified model.

\begin{tabular}{|c|c|c|c|}
\hline Model coefficients & Reference standards & The initial model & The modified model \\
\hline & Adaptation indexes & & \\
\hline CMIN & The less the better & 376.661 & 356.101 \\
\hline $\mathrm{df}$ & The greater the simpler of the model & 199 & 198 \\
\hline \multirow[t]{2}{*}{$P$-value } & $>0.05$ & 0 & 0 \\
\hline & Absolute fitting indexes & & \\
\hline GFI & $>0.9$ & 0.879 & 0.885 \\
\hline RMR & $<0.05$ & 0.062 & 0.06 \\
\hline \multirow[t]{2}{*}{ RMSEA } & $<0.05$ & 0.06 & 0.057 \\
\hline & Value-added adaptation indexes & & \\
\hline AGFI & \multirow{6}{*}{$>0.9$} & 0.846 & 0.853 \\
\hline NFI & & 0.869 & 0.876 \\
\hline CFI & & 0.933 & 0.94 \\
\hline RFI & & 0.848 & 0.855 \\
\hline IFI & & 0.934 & 0.941 \\
\hline \multirow[t]{2}{*}{ TLI } & & 0.922 & 0.93 \\
\hline & \multirow[t]{3}{*}{ Simple adaptation indexes } & & \\
\hline PCFI & & 0.804 & 0.806 \\
\hline PNFI & & 0.748 & 0.751 \\
\hline CMIN/DF & $(1,3)$ & 1.893 & 1.798 \\
\hline
\end{tabular}

\subsection{Empirical Results Analysis}

The calculation results of the coefficients and test values of the main model paths after debugging show that between the object level and the action level, the paths from upstream suppliers to both direct conversations and observation are significantly positive, while the path from other visitors to only observation is significantly positive. It shows that visitors talk more with suppliers in the exhibition, while other visitors learn more by observing others' behavior. By comparing path coefficients, the results show that visitors are more likely to talk to suppliers rather than observation, with the path coefficient of 0.75 . It indicates that visitors are more likely to communicate with upstream suppliers through direct conversations in the exhibition, while other visitors are more likely to observe suppliers' behavior.

Between the action level and the effect level, two learning styles' paths from direct conversations and observation to the learning effects of new technology and market trends are significantly positive. By comparing the path coefficients, the results show that the path coefficients from observation to two variables of effect level are both greater than 0.4 , while the path coefficient from direct conversations to only technology effect is greater than 0.4 . From the above results, visitors acquire more exhibition knowledge with observation rather than direct conversations. According to the interview results, there are too many suppliers and limited visiting time. So, visitors observe most of the booths and choose to 
talk to their interested suppliers for a short time, which can be the reason of the learning effect of observation being more obvious than that of direct conversations. According to the results of empirical analysis, the modified model of the learning and innovation process of exhibition visitors is constructed (can be seen in Figure 2).

\section{Conclusion, Suggestion and Discussion}

\subsection{Research Conclusion}

\subsubsection{The Learning Styles of Exhibition Visitors Depend on the Objects} Visitors adopt different learning styles with different participants in the exhibition. They can talk directly with exhibitors while observing the exhibits because of the fixed booths. As for other visitors with great mobility and strangeness, there are fewer conversations among visitors. Most visitors gain knowledge by indirectly observing the behavior of others, such as observing their tendency and listening in on their conversations.

\subsubsection{Positions Have an Impact on Learning Styles of Visitors}

Visitors in different positions of enterprises adopt slightly different learning styles. Middle and senior managers and technicians are more likely to talk directly to acquire knowledge than buyers, because they have more topics to talk to others than buyers. Also, middle and senior managers generally have a deep concern and understanding of market trends, while technicians have a higher understanding of industry's technology, so they can better talk about technological knowledge and market trends with other participants.

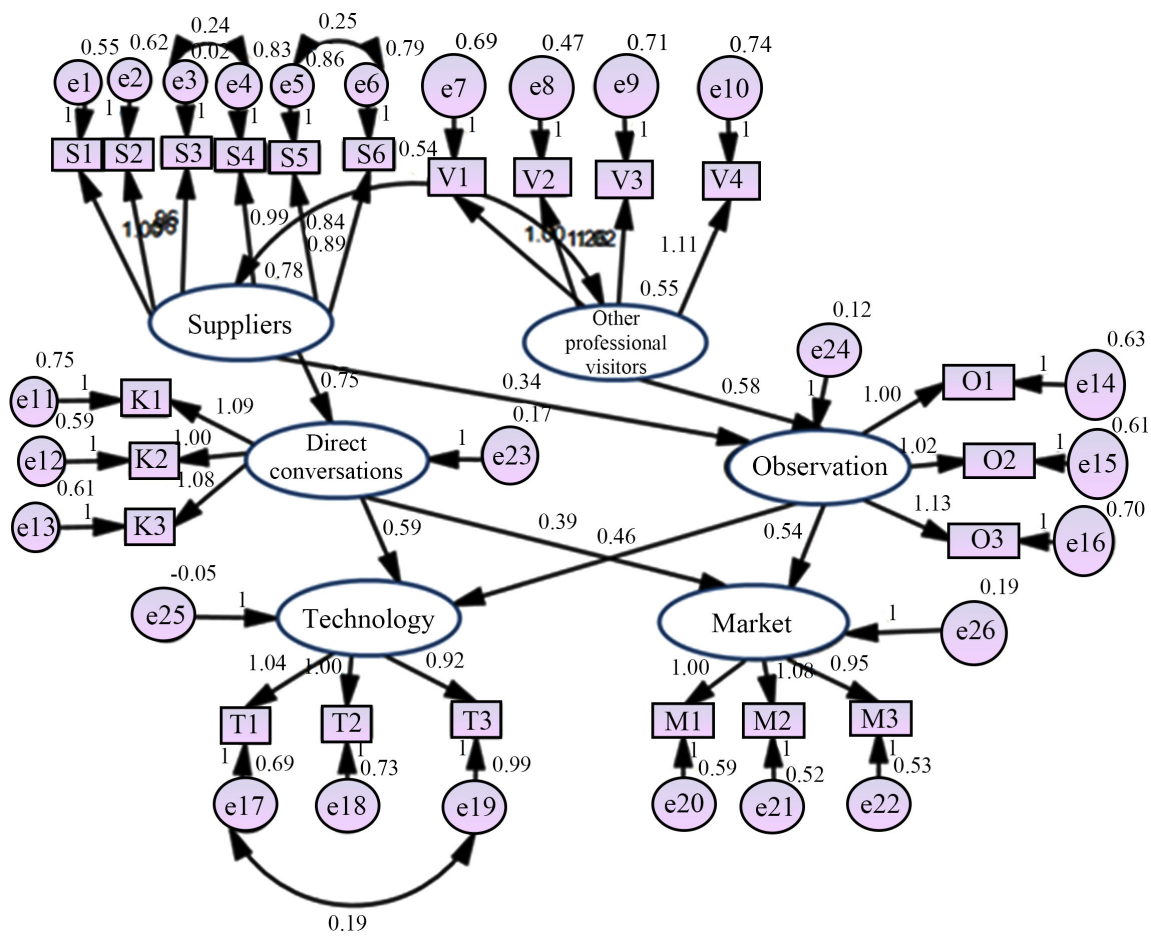

Figure 2. The modified model of visitors' learning and innovation. 


\subsubsection{The Visiting Forms Have Impacts on Both Learning Behavior and Effects}

The visiting forms of the visitors have impacts on both their learning behavior and effects. Visitors visiting in groups are more likely to communicate with other exhibition participants and get better learning effects than those visiting alone.

\subsubsection{Observation Is More Commonly Used by Visitors to Acquire Knowledge}

The results show that visitors acquire more knowledge with observation rather than direct conversations in the exhibition, which is mainly due to the limited visiting time, many tasks, and many objects to visit and learn. Visitors spend more time on communications which are more valuable and meaningful to them, and select the exhibition projects. They don't have in-depth communication on all exhibition projects.

\subsubsection{The Contents of Acquired Knowledge Have an Impact on Learning Styles}

Exhibition visitors acquire technological or market knowledge mainly through direct or indirect observation and conversations to promote their innovation. The results of this study show that the main ways of acquiring technological and market knowledge are observing, summarizing and comparing the exhibits on the spot and observing the interaction among other participants, while "direct conversations" are widely used to acquire technological knowledge.

\subsubsection{The Exhibition Focuses on Business Communications}

The results of samples survey show that they have relatively low evaluation on the effects of learning and innovation. It shows that the information, knowledge and technology acquired by participants have no obvious promotion for their knowledge and innovation, presenting the current characteristics of the exhibition. As one of the technological exhibitions in China, Shenzhen International Industrial Manufacturing Technology Exhibition has such little promotion on visitors' learning effects, not to mention other exhibitions.

\subsection{Suggestion}

\subsubsection{For Exhibition Facilities: Set up Sufficient Negotiation Areas to Promote Communications}

Some visitors talk more directly with suppliers in the exhibition, while other visitors take more indirect observation. For the organizers, more negotiation areas should be set up in the exhibition to provide convenience for conversations between visitors and suppliers, such as setting up special negotiation areas and increasing the width of the aisles.

\subsubsection{For Exhibitors: Make All Kinds of Preparations in Advance}

Exhibitors should make adequate preparations during the preparation for the exhibition. The preparation contents not only include exhibits and publicity 
materials, but also include the systematically training of exhibitors, so that they can better express the technological innovation of the enterprise and products' advantages in the market when talking to visitors. Also, the research conclusions show that middle and senior managers and technicians are more likely to talk directly, and visitors visiting in groups interact more with other participants than visitors visiting alone. Therefore, when inviting visitors, organizers and exhibitors should focus on potential visitors of middle and senior managers and technicians and invite more visitors visiting in groups.

\subsubsection{Improve the Display Ability and Effects of the Exhibition}

By observation, visitors can achieve better learning effects than those by direct conversations, which means that the organizers and exhibitors need to constantly improve the display form, integrate the emerging display technology, and provide better display effects for visitors.

\subsection{Discussion}

\subsubsection{The Samples Are Highly Targeted}

The paths of learning and innovation of exhibition visitors are studied by the methods of literature review, questionnaire survey and structural equation model, which is of theoretical and practical significance. However, the formal questionnaires were distributed through sending questionnaires in the machinery industry discussion group, sending questionnaires by e-mails and inviting visitors familiar to the researcher, which leads to the lack of randomness of samples and lack of representativeness of the visitors in industries. In this study, there is less discussion of visitors in other industries. Taking into account the relevance of the industries and the industrial chains, the collected data with not enough randomness also includes the information of visitors in other industries.

\subsubsection{Trade Platform and Technology Communication: A Game between Reality and Hope}

Samples have relatively low evaluation on the effects of learning and innovation after the exhibition, which fully reflects the essence and reality of the trade platform of the exhibition. However, many visitors participate in the exhibition with the purpose of learning new knowledge and new technology. Thus, the difference between their purpose and the actual function and effects of the exhibition occurs, which leads to two problems worthy of further research in the future. First, whether exhibitions need to strengthen or open up special mechanisms for promoting knowledge communication or not. Second, the knowledge promotion and technological innovation shown in this study are not enough, but further study should be conducted to find out that whether this is really the case in the reality after the exhibition.

\subsubsection{Further Evaluation of the Contents and Effects of Knowledge Promotion}

The highly targeted samples lead to the understanding limitation of other indus- 
tries or specialties to a certain extent. The visitors' evaluation of exhibition knowledge promotion and technological innovation vary with the following factors: the levels and contents of knowledge learned or promoted in the exhibition, their positions and their types of enterprises. Moreover, the visitors in this study would like to learn more about the relevant core technology and knowledge in the exhibition, so that they can improve themselves rapidly in future application, and this is hard to realize. Further studies should be conducted to find out whether the acquired knowledge which doesn't make much sense at that time plays an important role in their future work. Therefore, the extended new topic of "the application of the knowledge learned in the exhibition" can be further studied, which is also the suggestion of many respondents in this study.

\section{Research Significance and Main Contributions}

Through questionnaire survey and model fitting, this paper studies the different learning methods adopted by the audience in the face of different communicators in the exhibition and the differences of learning and innovation effects brought by different learning methods. In theory, it complements the theoretical research on the learning methods and effects of audience in the exhibition. In practice, it can help the organizers better design the exhibition and promote the effect of knowledge exchange through the exhibition.

\section{Conflicts of Interest}

The authors declare no conflicts of interest regarding the publication of this paper.

\section{References}

Albert, B. (2014). The Brilliant Road of Human Nature: Bandura's Social Learning Theory. Beijing: People's Publishing House.

Bathelt, H., \& Gibson, R. (2015). Learning in “Organized Anarchies”: The Nature of Technological Search Processes at Trade Fairs. Regional Studies, 49, 985-1002. https://doi.org/10.1080/00343404.2013.783691

Bathelt, H., Malmberg, A., \& Maskell, P. (2002). Clusters and Knowledge: Local Buzz, Global Pipelines and the Process of Knowledge Creation. Progress in Human Geography, 28, 31-56. https://doi.org/10.1191/0309132504ph469oa

Bollen, K. A. (1989). A New Incremental Fit Index for General Structural Equation Models. Sociological Methods \& Research, 17, 303-316. https://doi.org/10.1177/0049124189017003004

Borghini, S., Golfetto, F., \& Rinallo, D. (2006). Ongoing Search among Industrial Buyers. Journal of Business Research, 59, 1151-1159. https://doi.org/10.1016/j.jbusres.2006.06.005

Boschma, R. A., \& Ter Wal, A. L. J. (2007). Knowledge Networks and Innovative Performance in an Industrial District: The Case of a Footwear District in the South of Italy. Industry and Innovation, 14, 177-199. https://doi.org/10.1080/13662710701253441

Chi, M. J. (2013). Study of Service Quality Optimization of Exhibition Audience from the Angle of Experience. M.A. Thesis, Qingdao: Ocean University of China.

Guo, L. L. (2011). Research on Influencing Factors of Exhibition Visitor's Behavior of Attending Decision-Making. M.A. Thesis, Dalian: Dongbei University of Finance \& Eco- 
nomics.

Ji, W. D. (2012). Research on Relationships among Perceived Service Quality, Satisfaction and Behavioral Intention of Exhibition Visitors. M.A. Thesis, Tianjin: Tianjin University of Commerce.

Jia, X. F. (2012). The Study of Trade Visitors' Behavior at a Business Trade Show. M.A. Thesis, Beijing: Beijing International Studies University.

Li, D. Y. (2017). Service Quality Satisfaction Assessment Research from Visitors of Exhibition. M.A. Thesis, Tianjin: Tianjin University of Commerce.

Li, Y. F. (2018). Research on the Influence Factors of Knowledge Transfer of the Exhibition from the Temporary Industrial Cluster. M.A. Thesis, Guangzhou: South China University of Technology.

Liu, X. M. (2015). Empirical Study on Influential Factors Regarding the Re-Visit Intention of Book Fair Visitors: Case Studies of South China Book Festival and Guangzhou Book Fair 2014 and Hong Kong Book Fair 2014. M.A. Thesis, Guangzhou: South China University of Technology.

Luo, Q. J., \& Zhong, D. X. (2016). Knowledge Diffusion at Business Events: A Case Study. International Journal of Hospitality Management, 55, 132-141. https://doi.org/10.1016/j.ijhm.2016.03.007

Nonaka, I., Toyama, R., \& Konno, N. (2000). SECI, Ba and Leadership: A Unified Model of Dynamic Knowledge Creation. Long Range Planning, 33, 5e34. https://doi.org/10.1016/S0024-6301(99)00115-6

Polanyi, M. (1967). The Tacit Dimension. New York: Doubleday.

Qiao, X. Y. (2012). Research on the Exhibition Visitors' Decision-Making Influencing Factors. M.A. Thesis, Shanghai: East China Normal University.

Reychav, I. (2009). Knowledge Sharing in a Trade Show: A Learning Spiral Model. Vine, 39, 143-158. https://doi.org/10.1108/03055720910988850

Rogers, E. M. (2016). Diffusion of Innovation (4th ed.). Beijing: Publishing House of Electronics Industry.

Shan, S., Zeng, G., \& Zhu, Y. W. (2014). Role of Exhibition on Path of Technological Innovation-A Case of China International Industry Fair. Resource Development \& Market, 30, 843-846.

Storper, M., \& Venables, A. J. (2004). Buzz: Face-to-Face Contact and the Urban Economy. Journal of Economic Geography, 4, 351-370. https://doi.org/10.1093/jeg/4.4.351

Wang, M. (2014). Research on Indirect Influence of Booth Staff's Emotional Display on Visitor's Communication Intention. M.A. Thesis, Beijing: Beijing International Studies University.

Zhao, J. J. (2016). An Empirical Study of Perceived Features of Smarter Exhibition Based on IPA Assessment-A Case Study of Guangzhou. M.A. Thesis, Guangzhou: Guangzhou University.

Zhong, D. X., \& Luo, Q. (2018). Knowledge Diffusion at Business Events: The Mechanism. International Journal of Hospitality Management, 71, 111-119.

https://doi.org/10.1016/j.ijhm.2017.12.003

Zhu, H., Chen, K., \& Lian, Y. (2018). Do Temporary Creative Clusters Promote Innovation in an Emerging Economy?-A Case Study of the Beijing Design Week. Sustainability, MDPI AG, 10, 767. https://doi.org/10.3390/su10030767

Zhu, Y. W., \& Zeng, G. (2017). Learning and Innovation Process of Attenders in International Trade Fairs: A Case Study of China International Fair. Tourism Science, 31, $82-94$. 